\title{
Akurasi Geometri Garis Pantai Hasil Transformasi Indeks Air pada Berbagai Penutup Lahan di Kabupaten Jepara
}

\author{
Arief Wicaksono $^{1,2^{*}}$ dan Pramaditya Wicaksono ${ }^{1}$ \\ ${ }^{1}$ Departemen Sains Informasi Geografi, Fakultas Geografi, Universitas Gadjah Mada, Yogyakarta, 55281 \\ ${ }^{2}$ Magister Perencanaan Pengelolaan Pesisir dan Daerah Aliran Sungai, Fakultas Geografi, Universitas Gadjah Mada, \\ Yogyakarta, Indonesia. \\ *Email koresponden: arief.wicaksono08@mail.ugm.ac.id
}

Diterima: 2018-07-12 /Refisi: 2019-01-29 Disetujui: 2019-02-20

(12019 Fakultas Geografi UGM dan Ikatan Geograf Indonesia (IGI)

\begin{abstract}
Abstrak Garis pantai merupakan salah satu data dasar dalam pemetaan yang harus dijamin ketersediaannya. Pesisir di Indonesia memiliki variasi penutup lahan sehingga karakteristik indeks air dalam memperoleh data garis pantai perlu diketahui agar pemanfaatan indeks air menjadi efektif. Tujuan penelitian ini adalah menghitung akurasi geometri garis pantai menggunakan transformasi NDWI, MNDWI, dan AWEI pada penutup lahan berbeda. Garis pantai hasil indeks air diperoleh dari citra Landsat 8 OLI, sedangkan garis pantai referensi untuk uji akurasi diperoleh dari interpretasi visual citra PlanetScope. Standar penilaian ketelitian horizontal garis pantai hasil indeks air menggunakan Perka BIG No 15 Tahun 2014. Hasil penelitian adalah pada nilai akurasi geometri garis pantai skala 1:100.000, tidak ada satu pun indeks air yang mampu mengakomodasi perolehan garis pantai pada semua kelas penutup lahan. Variasi nilai akurasi geometri setiap indeks air disebabkan oleh variasi kondisi citra, karakteristik saluran yang digunakan dalam formula indeks air, dan piksel campuran.
\end{abstract}

Kata kunci: akurasi geometri; garis pantai; indeks air; penutup lahan; Landsat 8 OLI

\begin{abstract}
Shoreline is one of the basic data in mapping that must be guaranteed. Coastal area in Indonesia has a variety of land cover so the characteristics of the water index in obtaining shoreline data need to be understand in order to use the water index method effectively. The objective of this study is to assess the geometric accuracy of shoreline derived by water indices (NDWI, MNDWI, and AWEI transformations) on various land cover. Shoreline data is extracted from Landsat 8 OLI imagery, while the reference shoreline for accuracy assessment is obtained from visual interpretation of PlanetScope imagery. The horizontal accuracy standard of the shoreline derived by water index uses Perka BIG No. 15 in 2014. The result show that there is no single water index that can accommodate shoreline extraction on 1:100.000 scale shoreline map in all land cover classes. Variations in geometric accuracy values on each water index are caused by image condition variations, band characteristics used in the water index formula, and mixed pixels.
\end{abstract}

Keywords: geometric accuracy; shoreline; water indices; land cover; Landsat 8 OLI

\section{PENDAHULUAN}

Pesisir merupakan wilayah dengan proses yang dinamis, baik akibat proses alam maupun dipercepat oleh aktivitas manusia (Sunarto, 2004). Salah satu contoh dinamika di wilayah pesisir adalah perubahan garis pantai. Dengan wilayah Indonesia yang luas dan garis pantai yang sangat panjang akan membutuhkan waktu lama dalam perolehan data dan pemantauan garis pantai apabila dilakukan dengan survei terestrial pada seluruh wilayah Indonesia sehingga diperlukan cara ekstraksi garis pantai yang cepat dan akurat melalui citra penginderaan jauh sehingga proses pembaharuan data garis pantai dapat dilakukan dalam waktu singkat dan mampu melengkapi data garis pantai yang sulit diperoleh melalui survei terestrial dan survei hidrografi. Dikeluarkannya Peraturan
Kepala Badan Informasi Geospasial Nomor 15 Tahun 2014 tentang Pedoman Teknis Ketelitian Peta Dasar dapat dijadikan sebagai standar ketelitian peta garis pantai yang diperoleh melalui citra penginderaan jauh.

Citra Landsat cocok digunakan untuk memantau perubahan garis pantai karena merekam kondisi darat-laut secara global pada skala spasial puluhan meter selama 37 tahun, karakteristik multispektral, dan perolehan yang mudah Tucker et al. (2004). Pemetaan garis pantai menggunakan citra Landsat telah banyak dilakukan pada penelitian terdahulu dengan berbagai macam metode ekstraksi garis pantai (Rokni et al., 2014; Ji et al., 2015; Li \& Gong, 2016; Sarp \& Ozcelik, 2017). Saluran yang digunakan dalam deteksi garis pantai adalah saluran yang peka terhadap objek air berdasarkan karakteristik 
pantulan spektral objek air. Tubuh air punya serapan yang kuat pada saluran inframerah dekat dan tengah (740-2.500 nm) sehingga panjang gelombang ini digunakan untuk membedakan air dari tanah, vegetasi, bangunan, dan objek darat lainnya (Haibo et al., 2011).

Penelitian oleh McFeeters (1996), Xu (2006), dan Pardo-Pascual et al. (2012) membuktikan bahwa metode indeks air memiliki keunggulan dalam hal kemudahan penggunaan dan waktu pengolahan yang singkat untuk perolehan data garis pantai. Beberapa indeks air yang digunakan dalam penelitian ini adalah NDWI (McFeeters, 1996), MNDWI (Xu, 2006), dan AWEI (Feyisa et al., 2014). Masing-masing indeks air dibuat untuk tujuan tertentu sehingga keunggulan yang diberikan oleh indeks air pada lokasi tertentu akan hilang ketika diterapkan di lokasi lain. Padahal, pesisir di Indonesia, khususnya di Kabupaten Jepara memiliki lebih dari satu penutup lahan. Oleh karena itu, diperlukan penelitian lebih lanjut mengenai karakteristik indeks air dalam memperoleh garis pantai pada penutup lahan berbeda sehingga dapat mengakomodasi deteksi garis pantai pada beberapa kelas penutup lahan. Moore (2000) membagi sumber kesalahan dalam pemetaan garis pantai menjadi dua kategori, yaitu kesalahan akibat sumber data dan kesalahan akibat metode pengukuran yang digunakan. Kesalahan akibat sumber data dapat diketahui dari akurasi sumber data, sedangkan kesalahan akibat metode pengukuran dapat diketahui dari akurasi alat ukur yang digunakan, serta dapat diakibatkan oleh kesalahan dalam interpretasi visual pada citra (Moore, 2000) dan penentuan visual garis air tinggi ketika di lapangan (Boak \& Turner, 2005). Penelitian ini fokus membahas pada aspek sumber kesalahan akibat sumber data dan metode interpretasi digital pada citra sehingga dari latar belakang tersebut maka penelitian ini bertujuan untuk menghitung akurasi geometri garis pantai hasil transformasi NDWI, MNDWI, dan AWEI pada penutup lahan berbeda.

\section{METODE PENELITIAN}

\section{Deskripsi Wilayah}

Kabupaten Jepara memiliki 8 kecamatan yang memiliki wilayah pesisir, yaitu Kecamatan Kedung, Tahunan, Jepara, Mlonggo, Bangsri, Kembang, Keling, dan Donorojo. Bentuk lahan yang terdapat di pesisir Kabupaten Jepara pada skala regional terdiri dari bentuk lahan asal proses marin, fluvial, dan vulkanik berdasarkan penelitian dari Sunarto (2004). Masingmasing bentuk lahan ini menunjukkan bahwa proses yang terjadi di pesisir Kabupaten Jepara bervariasi sehingga menghasilkan pantai dengan material yang berbeda. Wilayah pesisir Jepara menghadap ke arah baratdaya, barat, baratlaut, dan utara. Faktor dari laut sangat berpengaruh besar terhadap wilayah darat pesisir Kabupaten Jepara. Karakteristik pasang surut diketahui dari penelitian Hutabarat et al. (1989) dan Kamiludin et al. (1991) dalam Sunarto et al. (2014).
Hasil perhitungan Indeks Formzal (F) oleh Kamiludin et al. (1991) diperoleh nilai 12,01 yang menunjukkan tipe pasang surut harian tunggal, yang berarti dalam sehari terjadi sekali pasang dan sekali surut. Besarnya julat pasang surut yang diteliti oleh Hutabarat et al. (1991) di Teluk Awur memperoleh hasil sebesar 94 $\mathrm{cm}$ sehingga wilayah penelitian termasuk mikropasut.

\section{Alat Dan Bahan Penelitian}

Objek dari penelitian ini adalah garis pantai dengan variasi penutup lahan di Kabupaten Jepara. Alat yang digunakan dalam penelitian ini antara lain, GPS navigasi untuk mengetahui posisi koordinat di lapangan, yalon dan pita ukur untuk mengukur jarak kemiringan pantai, abney level untuk mengukur kemiringan pantai, software ArcGIS 10.5 untuk digitasi dan penyajian data garis pantai, software ENVI 5.3 untuk mengolah citra satelit, dan Digital Shoreline Analysis System (DSAS) v4.4 untuk melakukan uji akurasi geometri garis pantai.

Bahan penelitian ini terdiri dari: 1) citra Landsat 8 OLI path 120/row 64 perekaman 18 Maret 2018 pukul 09:47:16, untuk memperoleh data garis pantai yang diperoleh dari www.earthexplorer.usgs.gov, 2) citra MODIS produk Aerosol Optical Depth (AOD) perekaman tahun 2018 untuk memperoleh nilai AOD dalam koreksi atmosferik metode FLAASH, yang diperoleh dari https://ladsweb.modaps.eosdis.nasa. gov, 3) citra SRTM 1 Arc-Second Global Coverage perekaman 23 September 2014 untuk memperoleh data elevasi wilayah penelitian pada koreksi atmosferik metode FLAASH dan membuat peta kemiringan lereng, yang diperoleh dari www.earthexplorer. usgs.gov, 4) citra PlanetScope wilayah Kabupaten Jepara perekaman 18 Maret 2018 pukul 09:20:29 dan 09:21:45, serta 19 Maret 2018 pukul 10:30:45, sebagai data referensi untuk uji akurasi geometri garis pantai, yang diperoleh dari www.planet.com, 5) peta Geologi skala 1:100.000 lembar Kudus yang diterbitkan oleh Pusat Penelitian dan Pengembangan Geologi tahun 1992 untuk membantu pembuatan peta tipologi fisik pesisir, dan 6) data prediksi pasang surut di Kabupaten Jepara tahun 2018 yang dikeluarkan oleh Badan Informasi Geospasial untuk koreksi pasang surut, yang diperoleh dari www.tides.big.go.id.

\section{Tahap Pengolahan Citra Landsat 8 OLI}

Nilai piksel citra Landsat 8 OLI yang digunakan untuk transformasi indeks air adalah sudah pada tahap at-sensor surface reflectance. Koreksi atmosferik menggunakan metode FLAASH karena metode ini mencoba memodelkan kondisi atmosfer mendekati kondisi sebenarnya di lapangan dengan membutuhkan beberapa informasi parameter terkait karakteristik sensor dan kondisi wilayah. Koreksi geometrik metode image-to-image registration dan koreksi pasang surut perlu dilakukan untuk memastikan bahwa perbedaan posisi garis pantai antara citra PlanetScope dan citra Landsat 8 OLI tidak disebabkan oleh kesalahan 
Tabel 1. Formula transformasi indeks air.

\begin{tabular}{lll}
\hline \multicolumn{1}{c}{ Jenis Indeks } & \multicolumn{1}{c}{ Formula } & $\begin{array}{c}\text { Nilai Piksel } \\
\text { Objek Air }\end{array}$ \\
\hline $\begin{array}{l}\text { Normalized } \\
\text { Difference Water } \\
\text { Index (NDWI) }\end{array}$ & $\begin{array}{l}\text { NDWI }= \\
\text { (GREEN-NIR) / }\end{array}$ & Positif \\
Modified Nor- & MNDWI $=$ & Positif \\
malized Differ- & (GREEN-SWIR1) / & \\
ence Water Index & (GREEN+SWIR1) & \\
(MNDWI) & & \\
Automated Water & AWEInsh =4 x & \\
Extraction Index & $($ GREEN - SWIR1) & \\
(AWEI) & $-(0,25 \times$ NIR + & \\
& $2,75 \times$ SWIR2) & \\
& AWEIsh = BLUE + & Positif \\
& $2,5 \times$ GREEN - 1,5 & \\
& $\mathrm{x}($ NIR + SWIR1) - & \\
& $0,25 \times$ SWIR2 & \\
\hline
\end{tabular}

geometri citra dan pengaruh variasi pasang surut, melainkan akibat keterbatasan kemampuan indeks air. Koreksi geometrik menggunakan 30 GCP dengan polynomial orde 2 menghasilkan RMSE sebesar 0,41. Formula indeks air yang digunakan dalam penelitian ini terangkum dalam Tabel 1 .

Untuk mengkelaskan piksel citra hasil indeks air menjadi kelas air dan non-air maka digunakan dua jenis threshold dalam penelitian ini, yaitu threshold $=0$ dan pengaturan threshold secara subjektif hingga diperoleh batas darat-laut yang paling mendekati garis pantai referensi yang didigitasi dari citra PlanetScope. Pemotongan citra pada beberapa sampel tipologi fisik pesisir dilakukan dengan batas berukuran 5 x $2,5 \mathrm{~km}$ untuk kebutuhan evaluasi threshold. Lokasi percobaan evaluasi threshold dipilih per sampel tipologi fisik pesisir dengan alasan bahwa hal ini merepresentasikan keadaan umum dalam pemanfaatan transformasi indeks air, yaitu bisa jadi dilakukan pada satu kelas tipologi fisik pesisir, tetapi terdiri dari beberapa kelas penutup lahan. Threshold subjektif ditentukan dari percobaan pada beberapa sampel tipologi fisik pesisir, yaitu dengan melihat nilai RMSE terendah dari masing-masing indeks air pada sampel tipologi fisik pesisir. Setelah itu, threshold subjektif dari setiap sampel tipologi fisik pesisir dibandingkan satu sama lain untuk menentukan satu threshold yang paling optimal pada setiap tipologi fisik pesisir lalu threshold tersebut diterapkan di seluruh wilayah penelitian.

\section{Tahap Koreksi Pasang Surut}

Kedudukan garis pantai yang digunakan pada setiap peta dapat berbeda tergantung pada tujuan pemetaan dan pemilihan garis kedudukan muka air laut. Penelitian ini menggunakan batasan operasional garis pantai kedudukan muka air laut pasang tertinggi karena data garis pantai yang diperoleh ditujukan untuk pengelolaan wilayah pesisir dan pulau-pulau kecil sehingga mengacu pada Undang-Undang No. 23 Tahun 2014 tentang Pemerintah Daerah. Agar data garis pantai dalam penelitian ini dapat diintegrasikan dengan peta lainnya yang menggunakan garis pantai dengan kedudukan muka air laut berbeda maka selain perlu memerhatikan sistem proyeksi dan datum yang digunakan, perlu juga dilakukan koreksi pasang surut dengan mengacu kedudukan muka air laut tertentu. Koreksi pasang surut diperlukan untuk memastikan bahwa perbedaan posisi garis pantai yang dihitung dalam uji akurasi tidak disebabkan oleh variasi pasang surut, melainkan karena keterbatasan transformasi indeks air citra dalam memisahkan darat-laut secara tepat. Koreksi pasang surut diawali dengan melihat tinggi pasang surut antara tanggal perekaman citra dan tanggal prediksi pasang surut. Keperluan koreksi pasang surut mempertimbangkan besarnya pengaruh variasi ketinggian muka air laut saat pasang dan surut yang dipengaruhi oleh kemiringan pantai dan resolusi spasial citra. Adapun perhitungan pergeseran garis pantai ketika terjadi perbedaan kondisi pasang surut antara garis pantai uji dan garis pantai referensi dilakukan menggunakan teori segitiga sikusiku mengacu penelitian Wicaksono et al. (2018).

\section{Tahap Pembuatan Peta Analisis: Tipologi Fisik Pesisir dan Penutup Lahan}

Pembuatan tipologi fisik pesisir ditentukan berdasarkan proses terjadi (genesis), relief, dan material penyusun. Data setiap parameter tersebut diperoleh dari peta geologi skala 1:100.000 lembar Kudus dan peta kemiringan lereng yang diturunkan dari citra SRTM. Klasifikasi tipologi fisik pesisir yang digunakan mengacu Shepard (1972) dalam Pethick (1984), dimana pesisir dikelompokkan menjadi dua kategori, yaitu pesisir primer dan pesisir sekunder. Untuk mempermudah pembuatan peta tipologi fisik pesisir maka digunakan matriks penentuan tipologi fisik pesisir (Rahardjo, 2003; Khakhim, 2009), sedangkan peta penutup lahan diperoleh dari interpretasi visual citra PlanetScope, dengan skema klasifikasi mengacu kelas penutup lahan skala 1:250.000 dalam SNI 764-1:2014 dengan beberapa modifikasi. Kondisi citra yang tidak bersih dari awan menjadi pertimbangan untuk tidak menggunakan klasifikasi multispektral karena akan menambah kesulitan akibat munculnya kelas-kelas yang tidak masuk akal. Sebanyak 116 sampel dikumpulkan di lapangan untuk uji akurasi peta penutup lahan. Metode penentuan sampel menggunakan stratified random sampling, yaitu pemilihan sampel secara acak dengan strata, yaitu berupa kelas penutup lahan.

\section{Tahap Pengujian Akurasi Geometri Garis Pantai}

DSAS dengan statistik shoreline change envelope (SCE) digunakan untuk menghitung besar perbedaan posisi antara garis pantai hasil indeks air dan garis pantai referensi. SCE menghasilkan informasi posisi koordinat $(\mathrm{X}, \mathrm{Y})$ garis pantai hasil indeks air, posisi 
koordinat $(\mathrm{X}, \mathrm{Y})$ garis pantai referensi, dan jarak antara kedua garis pantai tersebut (dalam satuan meter) pada setiap sampel transek yang dibuat. Dari informasi tersebut kemudian dapat dihitung RMSE horizontal menggunakan rumus berikut:

RMSE horizontal $=\sqrt{\frac{\sum\left(X_{p e t a-X} c e k\right)^{2}+\left(Y_{p e t a-}-Y_{c e k}\right)^{2}}{n}}$

$$
(\mathrm{BIG}, 2014)(1)
$$

Keterangan:

$\mathrm{n}=$ jumlah total pengecekan pada peta $\mathrm{X}=$ nilai koordinat pada sumbu $\mathrm{X}$ $\mathrm{Y}=$ nilai koordinat pada sumbu $\mathrm{Y}$ Setelah diketahui nilai RMSE horizontal maka selanjutnya dihitung akurasi geometri horizontal (Nilai CE90) yang diperoleh dengan rumus yang mengacu kepada standar US NMAS (United States National Map Accuracy Standards) berikut. CE90 $=1,5175 \times$ RMSEr $\quad(B I G, 2014)(2)$

Keterangan:

CE90 $=$ Circular Error 90\% adalah ukuran ketelitian geometri horizontal yang didefinisikan sebagai radius lingkaran yang menunjukkan bahwa 90\% kesalahan atau perbedaan posisi horizontal objek di peta dengan posisi yang dianggap sebenarnya tidak lebih besar dari radius tersebut. RMSEr $=$ Root Mean Square Error pada posisi $\mathrm{x}$ dan $\mathrm{y}$
Setelah diperoleh akurasi geometri garis pantai hasil indeks air pada masing-masing kelas penutup lahan berbeda maka selanjutnya dari akurasi geometri (dalam RMSE) lalu dikonversi ke dalam ketelitian horizontal (CE90) kemudian dibandingkan dengan kelas ketelitian horizontal yang mengacu Perka BIG No 15 Tahun 2014 tentang Pedoman Teknis Ketelitian Peta Dasar. Adapun standar ketelitian tersebut dapat dilihat pada Tabel 2. Standar tersebut dipilih karena merupakan skala terdekat antara skala penyajian peta hasil dengan skala peta dasar yang dikeluarkan oleh BIG, yaitu skala 1:100.000 dan 1:250.000 untuk peta RBI. Dengan begitu, dapat diketahui apakah masing-masing indeks air mampu atau tidak dalam memenuhi standar Perka BIG No 15 Tahun 2014 untuk memperoleh garis pantai pada penutup lahan berbeda. Lebih lengkap mengenai tahapan dari penelitian dapat dilihat pada Gambar 1.

Tabel 2. Ketelitian geometri peta rupabumi.

\begin{tabular}{|c|c|c|c|}
\hline \multirow[t]{2}{*}{ Skala } & \multicolumn{3}{|c|}{$\begin{array}{c}\text { Ketelitian Horizontal Peta RBI } \\
\text { (dalam m) }\end{array}$} \\
\hline & Kelas 1 & Kelas 2 & Kelas 3 \\
\hline $1: 100.000$ & 20 & 30 & 50 \\
\hline $1: 250.000$ & 50 & 75 & 125 \\
\hline
\end{tabular}

Sumber: Perka BIG No 15 Tahun 2014 (horizontal).

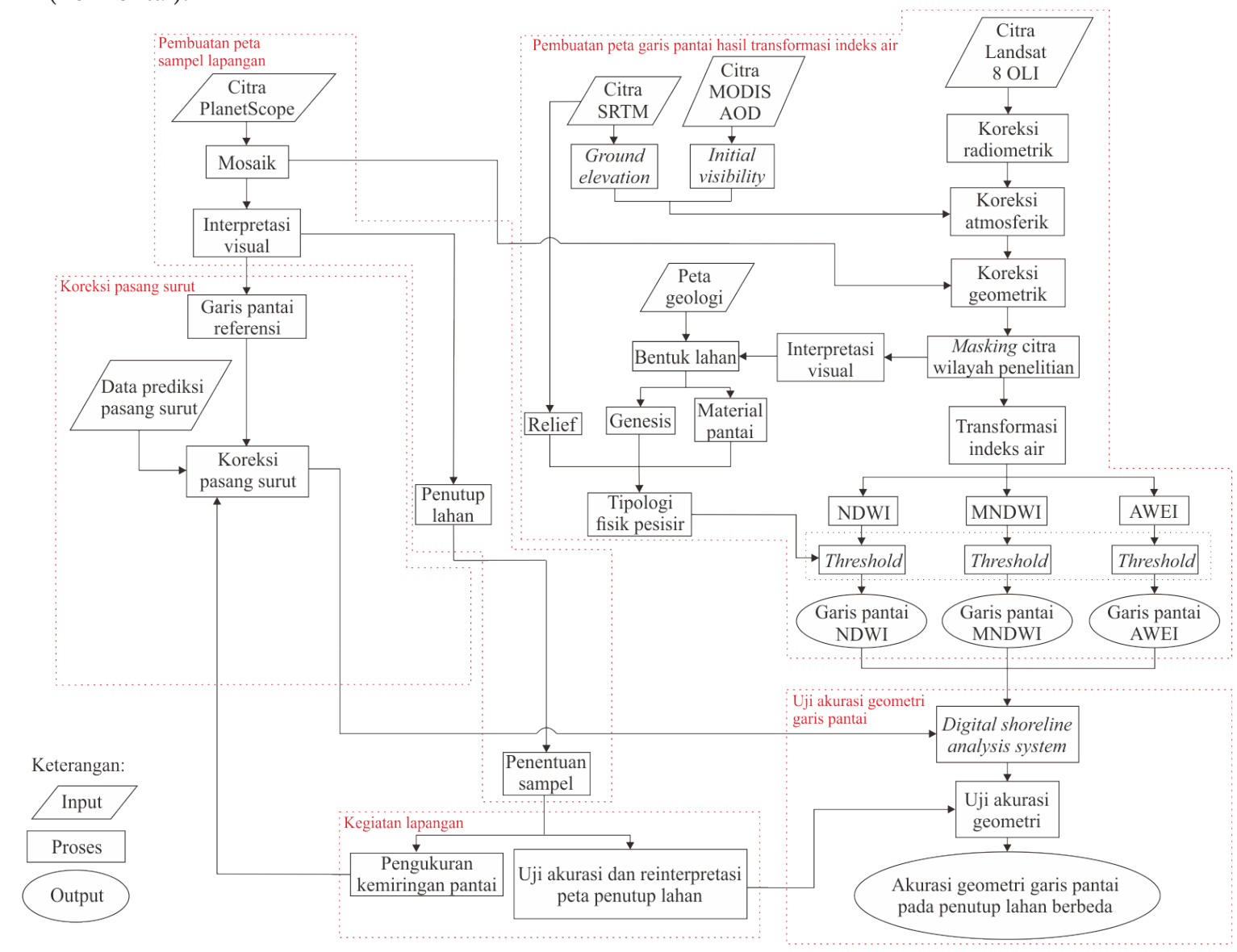

Gambar 1. Diagram alir penelitian. 


\section{HASIL DAN PEMBAHASAN}

Threshold optimal setiap indeks air pada masingmasing tipologi fisik pesisir yang akan diterapkan di seluruh wilayah penelitian disajikan pada Tabel 3 .

Threshold optimal memiliki nilai yang sama dengan threshold subjektif pada kelas tipologi fisik pesisir pengendapan laut. Alasan pemilihan threshold mengikuti threshold subjektif pada kelas tipologi fisik pesisir pengendapan laut adalah agar garis pantai dapat diperoleh di seluruh wilayah penelitian. Adapun ketika threshold yang dipakai memiliki nilai lebih rendah dan lebih tinggi dari threshold pada kelas tipologi fisik pesisir pengendapan laut maka secara pengamatan visual hal tersebut dapat merusak garis pantai pada kelas tipologi fisik pesisir pengendapan laut, artifisial, dan organik. Sementara itu, untuk kelas tipologi fisik pesisir pengendapan darat dan volkanik cenderung lebih stabil dan tidak berubah secara signifikan. Beberapa sumber kesalahan yang diidentifikasi pada masing-masing lokasi sampel antara lain tambak, sedimen, awan, bayangan awan, dan pelabuhan.

Terdapat sembilan garis pantai yang termuat dalam

Tabel 3. Threshold optimal setiap indeks air pada masing-masing tipologi fisik pesisir.

\begin{tabular}{lrrrr}
\hline Tipologi & \multicolumn{4}{c}{ Indeks Air } \\
\cline { 2 - 5 } Fisik Pesisir & NDWI & MNDWI & AWEIsh & AWEInsh \\
\cline { 2 - 5 } Artifisial & $-0,05$ & 0 & 0 & 0 \\
Organik & $-0,1$ & $-0,05$ & 0 & - \\
$\begin{array}{l}\text { Pengenda- } \\
\text { pan Laut }\end{array}$ & $-0,15$ & 0,15 & $-0,05$ & 0,05 \\
$\begin{array}{l}\text { Pengenda- } \\
\text { pan Darat }\end{array}$ & 0,2 & 0,3 & 0,1 & 0,05 \\
Volkanik & 0,2 & 0,3 & 0,15 & 0,05 \\
$\begin{array}{l}\text { Threshold } \\
\text { optimal }\end{array}$ & $-0,15$ & 0,15 & $-0,05$ & 0,05 \\
Sumber: Peng & & & &
\end{tabular}

Sumber: Pengolahan data (2018)
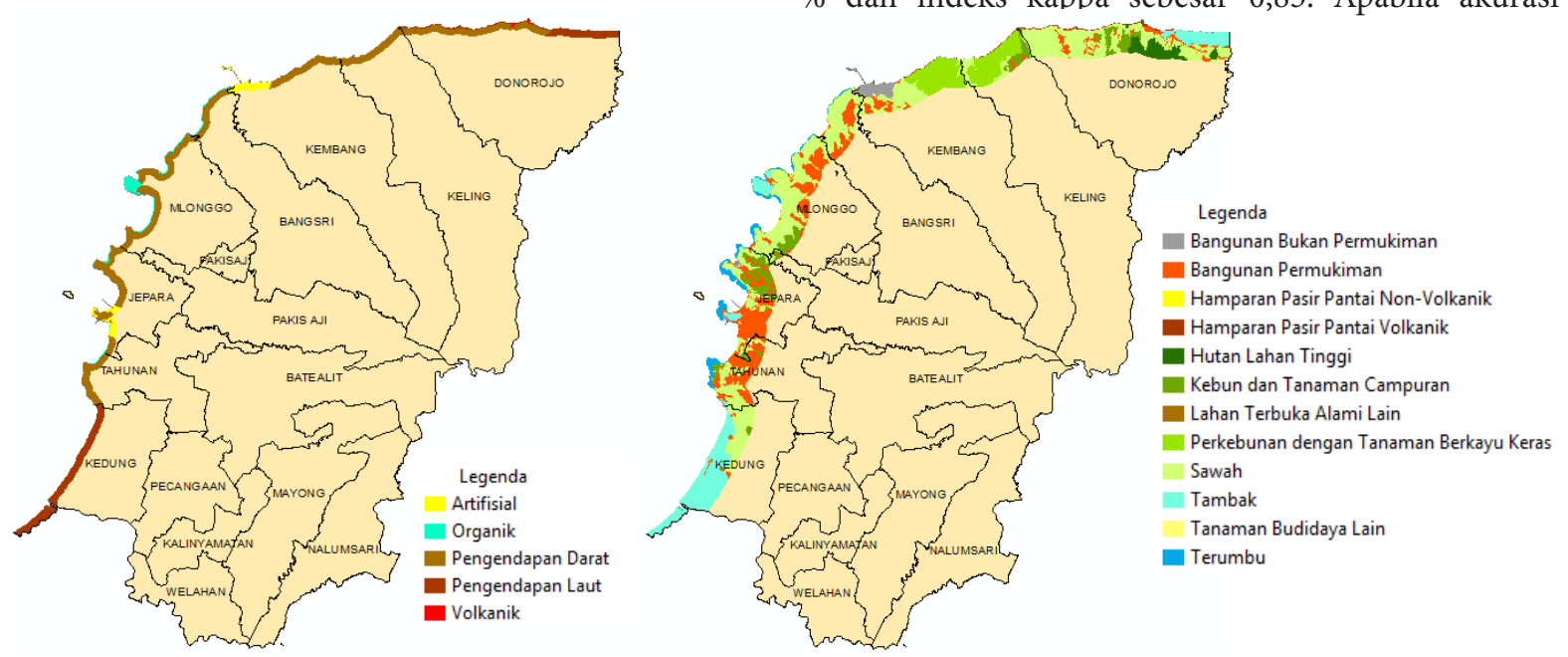

Gambar 2. Peta tipologi fisik pesisir (kiri) dan penutup lahan di pesisir (kanan) Kabupaten Jepara peta, yaitu satu garis pantai referensi dan delapan garis pantai hasil indeks air, dimana masing-masing indeks air menggunakan threshold 0 dan threshold subjektif. Beberapa lokasi penyajiannya diperbesar karena memiliki garis pantai hasil indeks air yang berbeda signifikan dengan garis pantai referensi. Proses generalisasi garis pantai menggunakan algoritma PAEK dengan nilai toleransi 200 karena dari pengamatan visual maka garis pantai yang dihasilkan lebih halus dan pola yang dibentuk menyerupai garis pantai referensi.

Data pasang surut mencatat bahwa pasang tertinggi pada tanggal 18 dan 19 Maret 2018 terjadi pada pukul 12.00. Kondisi ini sesuai dengan definisi garis pantai yang dipakai sehingga garis pantai yang diperoleh dari hasil pengolahan citra Landsat 8 OLI adalah garis pantai pada saat pasang. Besarnya pergeseran secara horizontal posisi garis pantai akibat pengaruh pasang surut adalah mulai dari 0,21 $\mathrm{m}$ hingga 1,8 m. Dengan demikian, koreksi pasang surut dalam penelitian ini tidak perlu dilakukan karena pergeseran secara horizontal posisi garis pantai akibat pengaruh pasang surut tidak terdeteksi pada citra PlanetScope karena pergeseran jaraknya kurang dari $3 \mathrm{~m}$. Apabila koreksi pasang surut tetap dilakukan, hal tersebut tidak akan mengubah akurasi geometri secara signifikan sehingga tahap koreksi pasang surut dapat dilewati.

Berdasarkan perbandingan antara panjang masingmasinggarispantaipadasetiapindeksair sepertidisajikan pada Tabel 4, diperoleh hasil yang berbeda-beda. Garis pantai referensi hasil interpretasi visual pada citra PlanetScope memiliki panjang 95.224,41 m, sementara garis pantai lainnya hasil indeks air memiliki panjang yang bervariasi antara $80.000 \mathrm{~m}$ hingga $100.000 \mathrm{~m}$.

Peta tipologi fisik pesisir dan penutup lahan disajikan pada Gambar 2. Dengan menggunakan tabel error matrix maka diperoleh akurasi keseluruhan peta tentatif penutup lahan sebesar $86,21 \%$ dan indeks kappa sebesar 0,84 . Sementara itu, akurasi keseluruhan peta tentatif tipologi fisik pesisir adalah sebesar 89,66 $\%$ dan indeks kappa sebesar 0,85. Apabila akurasi

\footnotetext{
(Pengolahan data, 2018).
} 
minimal yang diterima adalah sebesar $85 \%$ maka peta tentatif penutup lahan dan tipologi fisik pesisir yang telah dibuat dapat digunakan untuk analisis.

Agar akurasi geometri dari masing-masing indeks air dapat diperbandingkan maka transek garis pantai yang dibuat dengan bantuan DSAS perlu diseleksi sehingga RMSE yang dihitung adalah RMSE dari transek garis pantai yang dapat diidentifikasi oleh semua indeks air yang digunakan dalam penelitian, sementara untuk transek garis pantai yang hanya dapat diidentifikasi oleh sebagian indeks air maka dianggap sebagai keunggulan indeks air tertentu atas indeks air lainnya. Jumlah transek garis pantai yang digunakan untuk menghitung RMSE indeks air adalah sebanyak 1.186 transek. Berdasarkan Tabel 5 maka dapat diketahui keunggulan dan keterbatasan dari masing-masing indeks air dalam ekstraksi garis pantai pada berbagai penutup lahan.

Tabel 4. Akurasi geometri garis pantai di Kabupaten Jepara pada penutup lahan berbeda hasil transformasi NDWI, MNDWI, dan AWEI (dalam RMSE).

\begin{tabular}{lrrr}
\hline \multicolumn{1}{c}{ Garis Pantai } & \multicolumn{1}{c}{$\begin{array}{c}\text { Panjang } \\
(\mathrm{m})\end{array}$} & $\begin{array}{c}\text { Selisih } \\
\text { dengan } \\
\text { Referensi } \\
(\mathrm{m})\end{array}$ & RMSE \\
\hline Referensi Planet- & $95.224,41$ & - & - \\
Scope & & & \\
AWEInsh $\mathrm{t}=0$ & $83.494,58$ & $11.729,83$ & 30.08 \\
AWEInsh $\mathrm{t}=0,05$ & $82.499,69$ & $12.724,72$ & 38.41 \\
AWEIsh $\mathrm{t}=0$ & $85.167,14$ & $10.057,27$ & 27.06 \\
AWEIsh $\mathrm{t}=-0,05$ & $102.161,65$ & $6.937,23$ & 27.15 \\
MNDWI $\mathrm{t}=0$ & $88.773,50$ & $6.450,91$ & 25.33 \\
MNDWI $\mathrm{t}=0,15$ & $79.492,49$ & $15.731,93$ & 28.88 \\
NDWI $\mathrm{t}=0$ & $83.371,42$ & 11.853 & 43.77 \\
NDWI $\mathrm{t}=-0,15$ & $97.648,92$ & $2.424,50$ & 32.89 \\
\hline SWH: Analisi & & &
\end{tabular}

Sumber: Analisis data (2018)
Dari Tabel 5 dapat diketahui bahwa garis pantai pada penutup lahan yang paling konsisten ketika diekstraksi dengan semua transformasi indeks air secara berturutturut adalah perkebunan dengan tanaman berkayu keras (rata-rata RMSE 7,56 $\pm 5,75 \mathrm{~m}$ ), hutan lahan tinggi (rata-rata RMSE 9,43 $\pm 8,20 \mathrm{~m}$ ), kebun dan tanaman campuran (rata-rata RMSE 11,11 $\pm 8,85 \mathrm{~m}$ ), hamparan pasir pantai non-volkanik (rata-rata RMSE 11,51 $\pm 15,76$ $\mathrm{m})$, hamparan pasir pantai volkanik (rata-rata RMSE $14,29 \pm 13,32 \mathrm{~m}$ ), bangunan bukan permukiman (ratarata RMSE 16,42 $\pm 18,95 \mathrm{~m}$ ), sawah (rata-rata RMSE $15,19 \pm 20,23 \mathrm{~m}$ ), tambak (rata-rata RMSE 32,23 $\pm 39,40$ $\mathrm{m}$ ), bangunan permukiman (rata-rata RMSE $22,93 \pm 53,72 \mathrm{~m}$ ), dan lahan terbuka alami lain (ratarata RMSE 37,48 $\pm 57,13 \mathrm{~m}$ ). Dengan demikian, apapun metode ekstraksi garis pantai yang digunakan maka garis pantai pada penutup lahan perkebunan dengan tanaman berkayu keras memiliki akurasi geometri paling tinggi (RMSE paling rendah) dibandingkan dengan garis pantai pada penutup lahan lain.

Contoh perbedaan posisi garis pantai hasil setiap transformasi indeks air pada kelas penutup lahan disajikan pada Gambar 3. Dari Gambar 3 tersebut dapat dilihat bahwa kemampuan transformasi indeks air dalam ekstraksi garis pantai pada penutup lahan bangunan permukiman (Gambar A), kebun dan tanaman campuran (Gambar B), dan hamparan pasir pantai non-volkanik (Gambar E) mengalami kendala akibat adanya tutupan awan dengan ketebalan yang bervariasi di tiga lokasi tersebut. Pada penutup lahan sawah (Gambar C) dan hamparan pasir pantai volkanik (Gambar H), nilai piksel dipengaruhi oleh persentase pantulan spektral antara objek tanah dan tubuh air. Pada penutup lahan perkebunan dengan tanaman berkayu keras (Gambar D) dan hutan lahan tinggi (Gambar G), nilai piksel dipengaruhi oleh persentase pantulan spektral antara objek vegetasi, tanah, dan tubuh air. Pada penutup lahan tambak (Gambar F) dan lahan terbuka alami lain (Gambar J), nilai piksel

Tabel 5. Akurasi geometri garis pantai di Kabupaten Jepara pada penutup lahan berbeda hasil transformasi NDWI, MNDWI, dan AWEI (dalam RMSE).

\begin{tabular}{|c|c|c|c|c|c|c|c|c|c|c|c|}
\hline \multicolumn{12}{|c|}{ Kelas Penutup Lahan } \\
\hline $\begin{array}{c}\text { Indeks } \\
\text { Air }\end{array}$ & $\begin{array}{l}\text { Thres- } \\
\text { hold }\end{array}$ & $\begin{array}{c}\text { Bangunan } \\
\text { Bukan } \\
\text { Per- } \\
\text { mukiman }\end{array}$ & $\begin{array}{l}\text { Bangunan } \\
\text { Per- } \\
\text { mukiman }\end{array}$ & $\begin{array}{l}\text { Pasir } \\
\text { Non- } \\
\text { Volka- } \\
\text { nik }\end{array}$ & $\begin{array}{c}\text { Pasir } \\
\text { Vol- } \\
\text { kanik }\end{array}$ & $\begin{array}{l}\text { Hutan } \\
\text { Lahan } \\
\text { Tinggi }\end{array}$ & $\begin{array}{l}\text { Kebun } \\
\text { Cam- } \\
\text { puran }\end{array}$ & $\begin{array}{l}\text { Lahan } \\
\text { Terbuka }\end{array}$ & $\begin{array}{l}\text { Perke- } \\
\text { bunan }\end{array}$ & Sawah & $\begin{array}{l}\text { Tam- } \\
\text { bak }\end{array}$ \\
\hline \multirow[t]{2}{*}{ NDWI } & 0 & 18,47 & 64,78 & 26,73 & 17,37 & 12,86 & 17,81 & 54,18 & 8,99 & 33,67 & 79,18 \\
\hline & $-0,15$ & 28,65 & 9,56 & 19,31 & 28,85 & 13,58 & 13,65 & 57,53 & 9,61 & 28,72 & 54,07 \\
\hline \multirow[t]{2}{*}{ MNDWI } & 0 & 25,94 & 50,12 & 17,55 & 19,67 & 13,56 & 15,07 & 47,80 & 10,82 & 23,31 & 33,09 \\
\hline & 0,15 & 25,44 & 68,81 & 14,86 & 14,79 & 10,00 & 12,13 & 47,31 & 8,46 & 18,45 & 44,33 \\
\hline \multirow[t]{2}{*}{ AWEIsh } & 0 & 22,75 & 22,72 & 14,13 & 18,78 & 13,56 & 13,68 & 47,74 & 9,65 & 26,18 & 46,84 \\
\hline & $-0,05$ & 26,98 & 19,97 & 20,48 & 25,73 & 13,60 & 11,46 & 56,71 & 10,07 & 17,31 & 38,80 \\
\hline \multirow[t]{2}{*}{ AWEInsh } & 0 & 23,86 & 70,25 & 16,74 & 12,56 & 10,12 & 14,69 & 53,77 & 8,61 & 19,45 & 47,12 \\
\hline & 0,05 & 26,94 & 99,29 & 23,02 & 11,83 & 11,78 & 14,00 & 133,93 & 9,50 & 30,14 & 50,49 \\
\hline
\end{tabular}



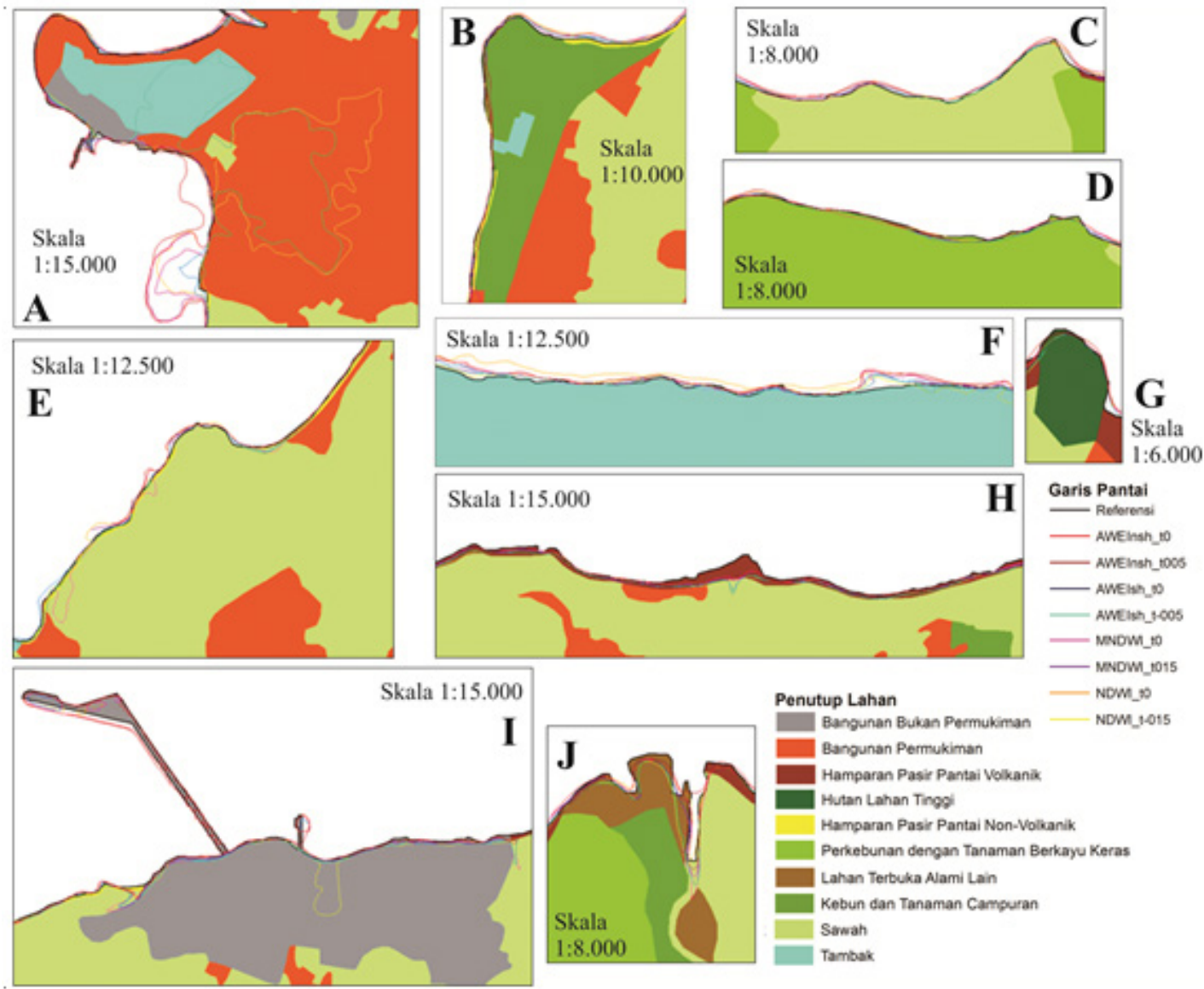

Gambar 3. Perbedaan posisi garis pantai hasil transformasi indeks air pada kelas penutup lahan.

dipengaruhi oleh pantulan spektral objek tanah basah, serta pada penutup lahan bangunan bukan permukiman (Gambar I), nilai piksel dipengaruhi oleh pantulan spektral objek aspal dan vegetasi.

Berkaitan dengan keunggulan dan keterbatasan dari masing-masing indeks air yang diperoleh dalam penelitian ini maka pernyataan Rokni et al. (2014) dan Sun et al. (2012) mengenai NDWI yang unggul dalam ekstraksi tubuh air pada penutup lahan sekitar berupa lahan non-terbangun dan perairan yang dekat dengan permukiman sesuai dengan hasil penelitian ini, yaitu pada ekstraksi garis pantai dengan penutup lahan sekitar berupa bangunan bukan permukiman, sementara untuk kelas penutup lahan pasir non-volkanik, pasir volkanik, hutan lahan tinggi, kebun campuran, perkebunan, dan sawah maka NDWI bukan indeks yang paling unggul dalam ekstraksi garis pantai yang berbatasan dengan kelas penutup lahan tersebut, tetapi NDWI masih layak untuk digunakan. Adapun objek yang termasuk kelas bangunan bukan permukiman terdiri dari bangunan perdagangan dan industri, serta tempat rekreasi. Sementara itu, keterbatasan NDWI dalam ekstraksi tubuh air pada penutup lahan sekitar berupa lahan terbangun sebagaimana dinyatakan oleh $\mathrm{Xu}$ (2006) juga didukung dengan hasil penelitian ini, yaitu keterbatasan dalam ekstraksi garis pantai dengan penutup lahan sekitar berupa bangunan permukiman. Akan tetapi, hal tersebut tidak berlaku untuk NDWI dengan threshold -0,15 karena justru merupakan indeks air yang paling unggul dibandingkan indeks air lainnya dalam ekstraksi garis pantai pada penutup lahan sekitar berupa bangunan permukiman sehingga dalam hal ini pengaturan threshold berperan dalam menentukan keunggulan dan keterbatasan masing-masing indeks air.

Sama halnya dengan NDWI, keunggulan MNDWI dalam ekstraksi tubuh air pada penutup lahan sekitar berupa lahan non-terbangun dan perairan dengan konsentrasi sedimen rendah sebagaimana dinyatakan oleh Xu (2006) dan Sun et al. (2012) didukung dengan hasil penelitian ini, tetapi keunggulan mengenai MNDWI yang mampu mengekstraksi tubuh air pada penutup lahan sekitar berupa lahan terbangun (Xu, 2006) tidak terbukti pada hasil penelitian ini karena akurasi geometri yang dihasilkan masih lebih rendah dibandingkan dengan AWEIsh. Hal ini terjadi disebabkan oleh lokasi penelitian Xu (2006), yang berada di sekitar perkotaan China, memiliki perbedaan kondisi atap dan lingkungan dibandingkan dengan wilayah penelitian di Kabupaten Jepara. Sementara itu, keterbatasan MNDWI dalam ekstraksi tubuh air di sekitar pelabuhan (Yang et al., 2015) dan perairan dengan sedimentasi tinggi (Sun et al., 2012) juga didukung dengan hasil penelitian ini. Walaupun begitu, MNDWI menghasilkan akurasi geometri paling rendah dibandingkan dengan indeks air lain dalam ekstraksi garis pantai dengan penutup lahan sekitar 
berupa lahan terbuka dan tambak, yang memiliki sedimen perairan dengan konsentrasi tinggi, tetapi MNDWI masih dinilai belum layak karena kelas ketelitian horizontalnya tidak memenuhi standar.

Keunggulan AWEI dalam ekstraksi tubuh air pada pantai dengan morfologi berlumpur sebagaimana dinyatakan oleh Li \& Gong (2016) tidak terbukti pada hasil penelitian ini, sementara keunggulan AWEI, khususnya AWEIsh, dalam menekan gangguan awan dan bayangan awan (Feyisa et al., 2014) terbukti efektif pada penelitian ini. Sementara itu, keterbatasan AWEI dalam ekstraksi tubuh air di sekitar pelabuhan (Yang et al., 2015) juga didukung dengan hasil penelitian ini, sedangkan kemampuan AWEI yang tidak sebaik NDWI dan MNDWI dalam ekstraksi tubuh air pada penutup lahan sekitar berupa lahan non-terbangun (Rokni et al., 2014) sebagian terbukti pada penelitian ini, yaitu pada kelas penutup lahan bangunan bukan permukiman, hutan lahan tinggi, dan perkebunan, sementara untuk kelas penutup lahan pasir non-volkanik, kebun campuran, dan sawah justru AWEIsh lebih unggul dibandingkan indeks air lainnya, serta untuk kelas penutup lahan pasir volkanik maka AWEInsh yang paling unggul.

Dari penjelasan di atas mengenai akurasi geometri garis pantai, dapat diketahui bahwa keunggulan dan keterbatasan dari setiap transformasi indeks air dalam ekstraksi garis pantai pada penutup lahan dapat dijelaskan dari saluran yang digunakan dalam formula indeks air dan karakteristik spektral objek. Akan tetapi, terkadang penjelasan tersebut tidak sesuai karena dipengaruhi oleh pemilihan threshold. Adanya ketidakkonsistenan dari karakteristik masing-masing indeks air terjadi akibat pengaturan threshold yang berbeda serta variasi kondisi citra. Selain itu, keberadaan piksel campuran akibat keterbatasan resolusi spasial citra mengakibatkan hasil klasifikasi menjadi salah karena hal ini berkaitan pula dengan variabilitas threshold, sebagaimana diteliti oleh Ji et al. (2009) dengan mencontohkan dinamika penentuan threshold pada NDWI dan diperoleh hasil bahwa dinamika threshold tergantung pada fraksi tanah dan vegetasi pada piksel campuran. Dengan demikian, dari penelitian ini maka diketahui bahwa tidak ada satu pun indeks air yang mampu mengakomodasi deteksi tubuh air dan ekstraksi garis pantai pada setiap kelas penutup lahan.

Dengan menghitung akurasi geometri garis pantai di Kabupaten Jepara pada penutup lahan berbeda dari hasil transformasi NDWI, MNDWI, dan AWEI menggunakan citra Landsat 8 OLI tahun 2018 maka dapat diketahui karakteristik dari transformasi NDWI, MNDWI, dan AWEI dan kelayakan penerapannya dalam ekstraksi garis pantai pada penutup lahan berbeda berdasarkan Peraturan Kepala BIG No 15 Tahun 2014 tentang Pedoman Teknis Ketelitian Peta Dasar sehingga pemanfaatan metode tersebut akan lebih efektif dan efisien. Dengan demikian, dapat disusun suatu panduan awal dalam pemilihan metode transformasi indeks air yang dapat menjadi pertimbangan bagi penelitian serupa ketika akan mengekstraksi garis pantai pada penutup lahan tertentu sebagaimana disajikan pada Gambar 4.

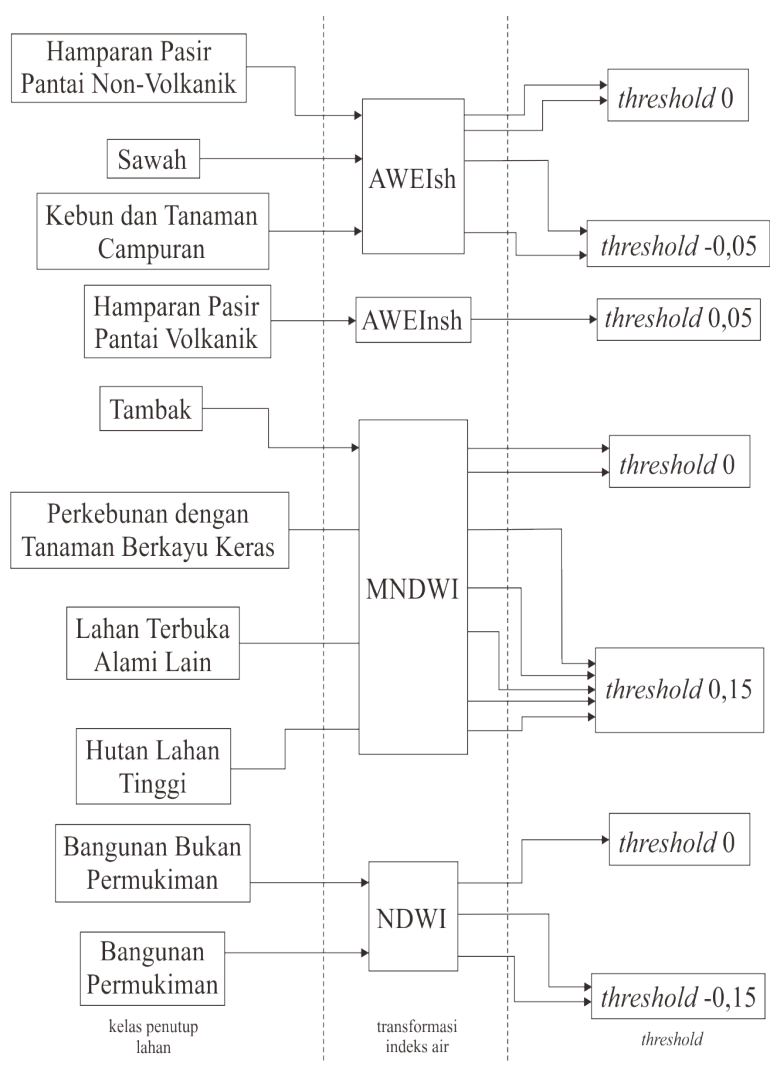

Gambar 4. Panduan awal dalam pemilihan metode transformasi indeks air untuk ekstraksi garis pantai pada berbagai penutup lahan.

\section{KESIMPULAN}

Panjang dan nilai akurasi geometri garis pantai dari masing-masing indeks air bervariasi disebabkan oleh variasi kondisi citra, karakteristik saluran yang digunakan dalam formula indeks air, dan piksel campuran. Keunggulan masing-masing indeks air dalam ekstraksi garis pantai pada penutup lahan diketahui dari akurasi geometri yang tinggi (RMSE rendah), sedangkan akurasi geometri rendah (RMSE tinggi) menunjukkan keterbatasan dari indeks air. Keunggulan dan keterbatasan dari masing-masing indeks air yang dinyatakan dalam penelitian ini hanya berlaku apabila dalam menerapkan transformasi indeks air untuk ekstraksi garis pantai maka terlebih dahulu wilayah penelitian harus dikelompokkan per kelas kelas penutup lahan agar pemanfaatan dari indeks air dalam ekstraksi garis pantai menjadi efektif. Penelitian ini baru mempertimbangkan variasi penutup lahan di darat, sementara untuk penutup lahan di laut belum dipertimbangkan sehingga diperlukan penelitian lebih lanjut mengenai kemampuan indeks air dengan membedakan jenis perairan berdasarkan konsentrasi zat yang terkandung di dalamnya karena 
hal tersebut berdampak pada karakteristik spektral perairan yang berbeda antara satu dengan yang lain.

\section{UCAPAN TERIMA KASIH}

Penulis mengucapkan terima kasih kepada Fakultas Geografi Universitas Gadjah Mada atas segala fasilitas dan bantuan yang mendukung kegiatan penelitian ini. Ucapan terima kasih juga penulis sampaikan kepada Dr. Nurul Khakhim, M.Si. dan Dr. Nur Mohammad Farda, M.Cs. dari Fakultas Geografi UGM yang telah memberikan beberapa masukan dalam penelitian ini.

\section{KONTRIBUSI PENULIS}

Penulis ke-1 mengumpulkan data, membuat naskah publikasi, mendesain topik penelitian, menyusun metode dan analisis data penelitian, serta interpretasi dan visualisasi hasil penelitian; Penulis ke-2 mendesain topik pembahasan, metode dan analisis data penelitian, serta review naskah publikasi.

\section{DAFTAR PUSTAKA}

Badan Informasi Geospasial. (2014). Peraturan Kepala Badan Informasi Geospasial Nomor 15 Tahun 2014 tentang Pedoman Teknis Ketelitian Peta Dasar. Boak, E. H., \& Turner, I. L. (2005). Shoreline Definition and Detection: A Review. Journal of Coastal Research, 21(4), 688-703. Feyisa, G. L., Meilby, H., Fensholt, R., \& Proud, S. R. (2014). Automated Water Extraction Index: A New Technique for Surface Water Mapping Using Landsat Imagery. Remote Sensing of Environment, 140, 23-35.

Haibo, Y., Zongmin, W., Hongling, Z., \& Yu, G. (2011). Water Body Extraction Methods Study Based on RS and GIS. Procedia Environmental Science, 10, 2619-2624.

Ji, L., Geng, X., Sun, K., Zhao, Y., \& Gong, P. (2015). Target Detection Method for Water Mapping Using Landsat 8 OLI/TIRS Imagery. Water, 7(2), 794-817.

Khakhim, N. (2009). Kajian Tipologi Fisik Pesisir Daerah Istimewa Yogyakarta untuk Mendukung Pengembangan dan Pengelolaan Wilayah Pesisir (Disertasi S3), Bogor: S3 Pengelolaan Sumberdaya Pesisir dan Lautan IPB.

Li, W., \& Gong, P. (2016). Continuous Monitoring of Coastline Dynamics in Western Florida with A 30-year Time Series of Landsat Imagery. Remote Sensing of Environment, 179, 196-209.

McFeeters, S. K. (1996). The Use of the Normalized Difference Water Index (NDWI) in the Delineation of Open Water Features. International Journal of Remote Sensing, 17(7), 1425-1432.
Moore, L. J. (2000). Shoreline Mapping Techniques. Journal of Coastal Research, 16(1), 121-139.

Pardo-Pascual, J. E., Almonacid-Caballer, J., Ruiz, L. A., \& Palomar-Vazquez, J. (2012). Automatic Extraction of Shoreline from Landsat TM dan ETM+ Multi-temporal Images with Subpixel Precision. Remote Sensing of Environment, 123, 1-11. Pethick, J. (1984). An Introduction to Coastal Geomorphology. London: Edward Arnold Ltd. Rahardjo, N. (2003). Sebaran Tipe Pantai dan Karakteristik Lingkungan di Pantai Selatan Jawa Barat. Majalah Geografi Indonesia, 17(2), 129-145.

Rokni, K., Ahmad, A., Selamat, A., \& Hazini, S. (2014). Water Feature Extraction and Change Detection Using Multitemporal Landsat Imagery. Remote Sensing, 6(5), 4173-4189.

Sarp, G., \& Ozcelik, M. (2017). Water Body Extraction and Change Detection Using Time Series: A Case Study of Lake Burdur, Turkey. Journal of Taibah University for Science, 11, 381-391.

Sun, F., Sun, W., Chen, J., \& Gong, P. (2012). Comparison and Improvement of Methods for Identifying Waterbodies in Remotely Sensed Imagery. International Journal of Remote Sensing, 6854-6875.

Sunarto. (2004). Perubahan Fenomena Geomorfik Daerah Kepesisiran di Sekeliling Gunungapi Muria Jawa Tengah: Kajian Paleogeomorfologi (Disertasi S3). Yogyakarta: S3 Ilmu Geografi UGM. Sunarto, Rahayu, E., \& Nugrahaeni, L. (2014). Deskripsi Lingkungan Wilayah Pesisir Jepara. Dalam Sunarto, M. A. Marfai, \& M. A. Setiawan, Geomorfologi dan Dinamika Pesisir Jepara (hal. 119-166). Yogyakarta: Gadjah Mada University Press.

Tucker, C. J., Grant, D. M., \& Dykstra, J. D. (2004). NASA's Global Orthorectified Landsat DataSet. Photogrammetric Engineering and Remote Sensing, 70(3), 313-322.

Wicaksono, A., Wicaksono, P., Khakhim, N., Farda, N.M., \& Marfai, M.A. (2018). Tidal correction effects analysis on shoreline mapping in Jepara Regency, Journal of Applied Geospatial Information, $2(2)$, pp. 145-151. doi: 10.30871/jagi.v2i2.981.

$\mathrm{Xu}$, H. (2006). Modification of Normalized Difference Water Index (NDWI) to Enhance Open Water Features in Remotely Sensed Imagery. International Journal of Remote Sensing, 27(14), 3025-3033. Yang, Y., Liu, Y., Zhou, M., Zhang, S., Zhan, W., Sun, C., \& Duan, Y. (2015). Landsat 8 OLI Image Based Terrestrial Water Extraction from Heterogeneous Backgrounds Using A Reflectance Homogenization Approach. Remote Sensing of Environment, 171, 14-32. 